\title{
Study on the Profit Distribution in Green Supply Chain System based on Cooperative Mode
}

\author{
LiangPing Tu' ${ }^{1}$, Yu Zheng ${ }^{2}$, XiaoLin Zhu ${ }^{2}$ \\ ${ }^{1}$ College of Science University of Science and Technology Liaoning, Anshan, Liaoning province, China \\ ${ }^{2}$ college of business administration University of Science and Technology Liaoning, Anshan, Liaoning province, China \\ \{bart.simpson \& homer.simpson\}@uspringfield.edu, monkey.king@uhuaguoshan.edu.cn
}

\begin{abstract}
The paper discusses the way of profit distribution of supplier and retailer and analyzes total profit which is based on cooperative mode in the green supply chain system. It determines the factor of profit distribution in this system and work out weighting value and coefficients and complete profit distribution of supplier and retailer.
\end{abstract}

Index Terms - Cooperative mode, green supply chain system, profit distribution

\section{Introduction}

With the environmental management idea in recent years were reviewed, constructing Green Supply Chain (GSC) has been one of important strategies to improve industries competitiveness for many enterprises. They need to develop green industries to reduce the environmental pollution in order to make enterprises own considerable development prospect. In the GSCS, both supplier and retailer must pay attention to green Gasification problems, while they pursuit profit maximization hardly.

Concil of Supply Chain Management Professionals of Michigan State University proposed that manufacturing supply chain exists environmental deterioration and such lower resources utilization and so on, they summarized negative factors of supply chain(SC) to environment and how to improve low efficiency using of resources. Under cooperation problems of alliance members of GSC , ZhangKeyong[1] researched the retailers' pricing coordination strategy in Closed-loop Supply Chain and make out that it is beneficial to improve retailers and cooperators' profits while retailers were based on flat concerning; DongJianxiao[2] researched cooperation games of supplier and retailer, and he hold that supplier and retailer mostly want the most interests so he obtained it needed to take related measures to standard the relation of supplier and retailer for Mutual Benefits and Common Wins .WangNengmin[3] hold that coordination mechanism works on SC while members cooperate, so they can own competition advantage which regard environmentfriendly as new elements for enterprises' development; Abroad,Jeremy Hall[4] proposed that each enterprise make sure how to coordinate relationship of both internal departments and cooperation enterprises in GSC, so as to optimize system environment and coordinate environmental management commonly; $\mathrm{Pal}[5]$ and other scholars choose enterprisers who implemented GSCM as the experimental objects to implement paper inquiry and they proposed that implementing GSCM can promote enterprises’ development.
Taking cooperative relation and GSC mode as premise, This paper is based on supplier and retailer can own more profits under cooperation mode which is other scholars' conclusions, and it obtains that GSCS can obtain the most profits under cooperation mode. And this paper uses Analytic Hierarchy Process and Fuzzy Comprehensive Evaluation Method to research some problems about profit distribution between supplier and retailer.

\section{Description of Problems and Hypothesis}

Cooperative mode this paper mentions means that supplier and retailer dominating resources alone convert to dominating resources commonly. It means that supplier and retailer obtain total competitive advantages to develop market commonly and take a risk and have the market share and change rigid management into flexible management .The paper assumes the GSCS exists an upstream supplier and a downstream retailer, they commonly supply green product to customers, in this case, supplier and retailer will own a common profit. So, the mode of their common profits of the GSCS was firstly proposed in the paper, and concrete hypothesis and symbol are as follows.

A. Supplier supplies a kind of green products costed $C_{m}$. Retailer sale them, which cost $C_{0}$. The products' selling cost in cooperation is $C_{r}$. Cooperation degree of them is $\phi$ in the GSCS; The paper assumes $C_{0}$ and $C_{r}$ exist the direct proportion: $C_{r}=f C_{0}$ and it means $C_{r} \leq C_{0}$.In fact, the cooperation cost of supplier and retailer decreases with cooperation degree increasing, and it will increase with cooperation degree increasing while this degree reaches to some degree, in one words, $f$ is one function about $\phi: f=f(\phi), f(\phi)$ meets $0 \leq f(\phi) \leq 1$ and $f(0)=1$ .It exists increased first and decreased afterwards, which is based on the proportion relation of both cooperation degree and cooperation cost and related function knowledge, this function $f=f(\phi)$ can be simplified represented by a two time function. In a word, it can make $f(\phi)=k \phi^{2}-a \phi+1, C_{r}=\left(k \phi^{2}-a \phi+1\right) \cdot C_{0}$, which have $a>0, k>0, \phi$ means cooperation degree between supplier and retailer. In fact, the value of $a, k$ may change with concrete 
situation of different fields and industries, which have $0 \leq \phi \leq 1$.

B. Selling price of this green product is $P_{r}$ and $P_{r}=(1+\xi)$ $P_{0}$, which $P_{0}$ is market price of common products and $\xi$ is selling price rising rate of green products.

$C$. The paper defines market demand of green products as $V\left(V<V_{h}\right)$, and $V_{h}$ expresses aggregate demand of market products ( green and non-green products).

D. $\prod$ expresses total profits under cooperation mode which is between supplier and retailer in the GSC.

Total profits is:

$$
\Pi=\left[(1+\xi) p_{o}-\left(k \phi^{2}-a \phi\right) C_{o}-C_{m}\right] V
$$

Supplier and retailer need to share resource in some degree and they will apply influences and control force to each other, and they can continue to distribute profit before they determine cooperate degree.

\section{Analysis of the Factors of Profit Distribution of the GSCS under Cooperation Mode}

A. Applying the method of analytic hierarchy process (AHP) to confirm the index weight

The problems of profit distribution are influenced by more factors under cooperation mode during profit distribution, such as cooperation investment, risk factors, environment management ability. Concrete situation are in Tab-1 as follows.

TABLE I The Evaluation Index System of Profit Distribution Between Supplier And Retailer[6]

\begin{tabular}{|c|c|c|}
\hline \multirow{10}{*}{$\begin{array}{l}\text { the factors of profit } \\
\text { distrib-ution } \\
\text { between supplier } \\
\text { and retailer( } A \text { ) }\end{array}$} & \multirow{3}{*}{$\begin{array}{c}\text { cooperation } \\
\text { investment }\left(A_{1}\right)\end{array}$} & $\operatorname{Human}\left(A_{11}\right)$ \\
\hline & & Material resources $\left(A_{12}\right)$ \\
\hline & & Financial resources $\left(A_{13}\right)$ \\
\hline & \multirow{3}{*}{ risk factors $\left(A_{2}\right)$} & Market risk $\left(A_{21}\right)$ \\
\hline & & Internal management $\operatorname{risk}\left(A_{22}\right)$ \\
\hline & & Cooperation risk $\left(A_{23}\right)$ \\
\hline & \multirow{4}{*}{$\begin{array}{c}\text { environment } \\
\text { management } \\
\text { ability }\left(A_{3}\right)\end{array}$} & Emission of three wastes ratio $\left(A_{31}\right)$ \\
\hline & & Energy utilization ratio $\left(A_{32}\right)$ \\
\hline & & ISO14000 Certification $\left(A_{33}\right)$ \\
\hline & & Product recovery ratio $\left(A_{34}\right)$ \\
\hline
\end{tabular}

\section{B. Special situation of determinate indexes}

1) Cooperation investment

Cooperation investment means all kinds of resources which supplier and retailer input in the cooperation. Furthermore, it calculates human through staff wages, but it should be calculated one more time if there is travel charges;
Material resources can expressed by funds; Financial resources mostly means factual fund during the cooperating.

2) Market risk

There exists risk for supplier and retailer in the GSCS because of competition of rivals, market trend and satisfactory rate of consumers. The factor set is:

$A_{21}=$ ratio of the same industries $\left(A_{211}\right)$, demand ratio of sub stitutes $\left(A_{212}\right)$, rate of complaint $\left.\left(A_{213}\right)\right\}$

3) Internal management risk

The paper will analyze the factor from qualified ratio of products, success rate of trade and technology ratio. The factor set is:

$A_{22}=$ \{qualified ratio of products $\left(A_{221}\right)$, success rate of trade$\left(A_{222}\right)$, technology ratio $\left.\left(A_{223}\right)\right\}$

4) Cooperation risk

The subtle relationship between supplier and retailer is influenced by many factors. The factor set is:

$A_{23}=\left\{\right.$ the input ratio of projects $\left(A_{231}\right)$, the breach ratio of enterprises $\left(A_{232}\right)$, ratio of not in time communication $\left.\left(A_{233}\right)\right\}$

5) Emission of three wastes ratio

It is the degree of waste water and waste gas and waste residue during production and selling the green products.

6) Energy utilization ratio

The index reflects the utilization ratio of all kinds of resources, which is a positive index.

7) ISO14000 Certification

IS014000certification is to constraint unfair environmental behaviors. It's a negative index.

8) Product recovery ratio

Product recovery ratio is a negative index, the index should be evaluated by investigation questionnaire. Hereby, the factor set is $D_{4}=($ Low, Lower, Meduim, higher, high $)$, the values of the factors are $D_{4}=(0.1,0.3,0.5,0.7,0.9)$.

\section{Establishing of judgment matrix}

Invest experimented experts(10 people) to analyze and work out the values of the factors. Then the papers analyzes every factors through 1-9 scale method, and compare each two factors, then, work out corresponding judgment matrix. Then, judge the consistency of it. The verdict matrix and benefit distributing coefficient are shown as follows.

$\left.A=\mid \begin{array}{cccc}a_{11} & a_{12} & \cdots & a_{1 n} \\ a_{21} & a_{22} & \cdots & a_{2 n} \\ \vdots & \vdots & \vdots & \vdots \\ a_{n 1} & a_{n 2} & \cdots & a_{n n}\end{array}\right\rfloor, a_{i j}$ is the important of index $i$ compared with $j$

So, the first grade indexes respectively cooperation investment $\left(A_{1}\right.$ ),risk factors ( $\left.A_{2}\right)$, environment management 
ability $\left(A_{3}\right)$ and the judgment matrix of second grade indexes is Market $\operatorname{risk}\left(A_{21}\right)$, Internal management $\operatorname{risk}\left(A_{22}\right)$, Cooperation risk $\left(A_{23}\right)$. The judgment matrix worked out need to judge the consistency, then worked out maximum eigenvalue $\lambda_{\max }$, CI $\left(C I=\left(\lambda_{\max }-n\right) /(n-1)\right)$, RI and CR (Random coincidence coefficient ).It's different to judge accordance from different methods based on whether verdict matrix is accordance or not. It need to introduce mean random consistency index RI if you to judge reasonable of accordance of different order verdict matrix, and values of RI is showed as attached-1.After CI and CR are obtained, the smaller the value of $\mathrm{CI}$ and $C R=\frac{C I}{R I}<0.10$, the more reasonable accordance the verdict matrix is.

The verdict matrix and benefit distributing coefficient are shown as follows.

1) Coefficient of cooperation investment $\left(A_{1}\right)$ follows.

Determination ways of this coefficient of factors is as

$$
I=I_{l}+I_{m}+I_{f}
$$

Determination Ways of human $\left(I_{l}\right)$, material resources $\left(I_{m}\right)$ and financial resources $\left(I_{f}\right)$ is that Coefficient of cooperation investment equals human plus material resources plus financial resources by monetary form.

2) Coefficient and weight vector of risk factors $\left(A_{2}\right)$

The paper uses fuzzy comprehensive estimate method and analyze of its characteristics to calculate coefficient of risk factors. Through analyzing market factors and binding fuzzy comprehensive estimate method, its factor aggregate is as follows.

$$
A_{21}=\left\{\text { ratio of the same industries }\left(A_{211}\right)\right.
$$
demand ratio of substitutes $\left(A_{212}\right)$, rate of complaint $\left.\left(A_{213}\right)\right\}$ , weight vector of risk factors is $M_{1}=\left(m_{1}, m_{2}, m_{3}\right)$, Corresponding evaluation set of factors is $M_{2}=$ (Low, Lower, Meduim, higher, high) ,Correspondin $\mathrm{g}$ value is $M_{3}=(0.1,0.3,0.5,0.7,0.9)$.After the evaluation set and corresponding value are given. By the experts' carefully evaluation, fuzzy matrix can be obtained and it can be defined as $M_{4}$, so we can obtain fuzzy comprehensive judgment vector, and it should be normalized if $\sum M_{5 i} \neq 1(i=1,2,3,4,5)$.

Coefficient of risk factors is as follows. $R_{m}=M_{5} \cdot M_{3}{ }^{T}$ Through analyzing and calculating and corresponding weight vector of internal management risk and cooperation risk are ditto $I_{1}=\left(i_{1}, i_{2}, i_{3}\right), C_{1}=\left(c_{1}, c_{2}, c_{3}\right)$, and their weight vector is $R_{i}, R_{c}$. The coefficient of total risk factor is,

$$
R=1-\left(1-R_{m}\right) \cdot R_{i} \cdot\left(1-R_{c}\right)
$$

3) Coefficient and weight vector of environment management ability

The paper uses fuzzy comprehensive estimate method and analyzes of this factor.

$A_{3}=\left\{\right.$ Emission of three wastes ratio $\left(A_{31}\right)$, ISO14000 Certification $\left(A_{32}\right)$, ISO14000 Certification $\left(A_{33}\right)$, Product recovery ratio $\left.\left(\mathrm{A}_{34}\right)\right\}$, then we can obtain the weight vector and the corresponding evaluation set of factors $E_{1}=\left(e_{1}, e_{2}, e_{3}, e_{4}\right)$ and $E_{2}=$ (poor, so-so, common, good, better $)$, the value of $E_{2}$ is $E_{3}=(0.1,0.3,0.5,0.7,0.9)$, and the fuzzy matrix is $E_{4}$, so we can obtain fuzzy comprehensive judgment vector, $E_{5}=E_{4} \cdot E_{1}$. Coefficient of environment management ability is as follows.

$$
E=E_{5} \cdot E_{3}^{T}\left(\sum E_{5 i} \neq 1(i=1,2,3,4,5)\right.
$$

The value of $E$ can reflect the environment management ability, and it is needed in the GSCS.

\section{The Profit Distribution In GSCS Which Based On Cooperative Mode}

The profit distribution weigh of supplier is $w_{1}$ and the weigh of retailer's is $w_{2}$, and they meet $w_{1}+w_{2}=1 ; I_{1}$ and $I_{2}$ respectively are total investment of supplier and retailer. $R_{1}$ and $R_{2}$ respectively are the enterprises'risk coefficient. $E_{1}$ and $E_{2}$ respectively are enterprises' environment management ability coefficient.

We obtain two Formula based on (2),(3) and (4),

$$
\begin{aligned}
& w_{1}=\frac{I_{1} \cdot R_{1} \cdot E_{1}}{I_{1} \cdot R_{1} \cdot E_{1}+I_{2} \cdot R_{2} \cdot E_{2}} \\
& w_{2}=\frac{I_{2} \cdot R_{2} \cdot E_{2}}{I_{1} \cdot R_{1} \cdot E_{1}+I_{2} \cdot R_{2} \cdot E_{2}}
\end{aligned}
$$

(2),(3) and (4) are the weigh of profit distribution of supplier and retailer in GSCS, and the enterprises' profits can be worked out by binding (1) in the cooperation.

$$
\begin{aligned}
& \Pi_{1}^{\prime}=\left[(1+\xi) p_{o}-\left(k \phi^{2}-a \phi+1\right) C_{o}-C_{m}\right] V \cdot w_{1} \\
& \prod_{2}^{\prime}=\left[(1+\xi) p_{o}-\left(k \phi^{2}-a \phi+1\right) C_{o}-C_{m}\right] V \cdot w_{2}
\end{aligned}
$$

$\Pi_{1}^{\prime}$ and $\prod_{2}^{\prime}$ is their cooperating profits in the GSCS.

\section{A. First Conclusion}

The paper carefully explains possibility of the cooperation and standard of profits distribution, and 
cooperation degree also influence their profits in the GSCS, so the optimal cooperation degree is $\phi=\frac{a}{2 k}$. proof Based on (1), solve $\frac{d \prod}{d \phi}=0, \phi=\frac{a}{2 k}$. The function is convex and the opening is downward. The profit of the GSCS meets $\phi=\frac{a}{2 k}$, the biggest profits is as follow.

$$
\Pi^{\prime}=\left[(1+\xi) p_{o}+\left(1-\frac{a^{2}}{4 k}\right) C_{o}-C_{m}\right] V
$$

The total profit and the grown are influenced by cooperation degree, so they can obtain the biggest profit if their cooperation degree is nearby $\phi=\frac{a}{2 k}(0 \leq \phi \leq 1)$.

\section{B. Second Conclusion}

They need to consider cooperation investment, risk factors and environment management ability when they distribute profit. Based on (5),(6),(7)and(8),the profit is as follows.

$$
\left\{\begin{array}{l}
\Pi_{1}^{\prime}=\Pi \cdot \frac{I_{1}}{I_{1}+I_{2}} \\
\Pi_{2}^{\prime}=\Pi I^{\prime} \frac{I_{2}}{I_{1}+I_{2}}
\end{array}\right.
$$

So, the more cooperation investment of supplier inputs, the more profit the supplier wins. In other words, the larger cooperation investment value $I_{1}$ is, the more profit the supplier obtains. In other side, retailer will obtains more profit when retailer inputs more invest and the cooperation investment value $I_{2}$ is larger than supplier. Above all, It meets $I=I_{1}+I_{2}$.

\section{Third Conclusion}

The profit of retailer and supplier will be influenced by risk factors. The supplier will obtain more profit when supplier bears more risk than retailer. It assumes not to consider other factors but risk factors in order to work out the profit of supplier and retailer analyze by using(5),(6),(7) and(8).The expressions of profit is as follows.

$$
\left\{\begin{array}{l}
\Pi_{1}^{\prime}=\Pi^{\prime} \frac{R_{1}}{R_{1}+R_{2}} \\
\Pi_{2}^{\prime}=\Pi^{\prime} \frac{R_{2}}{R_{1}+R_{2}}
\end{array}\right.
$$

So, the more risk supplier bears, the more profit the supplier wins; In other words, the larger risk factors value $R_{1}$ is, the more profit the supplier obtains. In other side, retailer will obtains more profit when retailer bears more invest and the risk factors value $I_{2}$ is larger than supplier. Above all, It meets $R=R_{1}+R_{2}$.

\section{The forth Conclusion}

It will obtain more profits if he bears more environmental responsibility and more contribution. Anylysis of (5),(6),(7) and(8).The expressions of profit is as follows.

$$
\left\{\begin{array}{l}
\Pi_{1}^{\prime}=\Pi^{\prime} \frac{E_{1}}{E_{1}+E_{2}} \\
\Pi_{2}^{\prime}=\Pi^{\prime} \frac{E_{2}}{E_{1}+E_{2}}
\end{array}\right.
$$

So, the larger environment management ability value $E_{1}$ is, the more profit the supplier obtains. It meets $E=E_{1}+E_{2}$.

Above all, profits distribution of supplier and retailer will be influenced by so many factors. This paper only propose cooperation investment, risk factors and environment management ability to distribute the profits and the profit and requirement of each other.

\section{Conclusions}

Based on (1), supplier and retailer will be influenced by so many factors if they want to obtain the largest profits. Cooperation degree is one of the important factors. The paper works out the cooperation degree by using property function of the mode in order to seek maximum profit. The calculation of profit is reasonable, which is based on the properties of Convex Function.

Based on (2)-(12), the profits of each other are obtained by using fuzzy comprehensive evaluation method, applying hierarchy method and analyzing of factors.

This paper analyze the factors of profits distribution and considers environment management ability, and it's different from other ways of profits distribution. On the factors, the paper comprehensively evaluate the three factors, and the paper gives the ways of calculations of the weigh and the theoretical results of profits distribution. The problem of profits distribution is one of the important society problems, and the scientific ways of profits distribution is very useful for enterprises' relation, so it is effective to improve enterprises' profits and social value.

\section{References}

[1] ZhangKeyong, Wuyan, HouShiwang. Study on pricing strategies of closed-loop supply chain under retailers' fair concern. Journal of Shandong University (Natural science edition), 2013 (5):84-91.

[2] DongJianxiao. Bo-Yi Analysis and Suggestions or Countermeasures of supplier and retailer. Enterprise management, 2012(11):39-43.

[3] WangNengmin, YangTong. Study on coordination mechanism of green supply chain. enterprise economic, 2006(5):13-15.

[4] Jeremy Hall. Environmental Supply Chain Dynamics. Journal of Cleaner Production, 2000, (8):455471

[5] Bose I, Pal R. Do green supply chain management initiatives impact stock prices of firms. Decision Support Systems, 2012, 52(3): 624-634.

[6] Wangnengmin. Choosing of Supplier for Green Manufacturing. System Engineering, 2001, 19(2): 30-35. 